\title{
BENEFÍCIOS E DIFICULDADES ENCONTRADAS NO PROCESSO DE SELEÇÃO DE PESSOAS: UMA ANÁLISE DO MODELO DE SELEÇÃO POR COMPETÊNCIAS, SOB A ÓTICA DE PROFISSIONAIS DA ÁREA DE GESTÃO DE PESSOAS BENEFITS AND DIFFICULTIES ENCOUNTERED IN THE PROCESS OF SELECTING PEOPLE: ANALYSIS OF THE SELECTION MODEL OF COMPETENCIES BY OPTICAL PROFESSIONALS IN THE FIELD OF PEOPLE MANAGEMENT
}

Dércia Antunes de Souza

Data de envio: 11/02/2011 Doutoranda em Administração de Empresas pela USCS - Universidade Municipal de São Caetano do Sul Data de aceitação: 04/08/2011

Claudiane Reis da Paixão

Doutoranda em Administração de Empresas pela UNINOVE

Edna Alves B. Souza

Especialista em Marketing pela Universidade Presbiteriana Mackenzie.

\section{RESUMO}

O presente trabalho tem por objetivo analisar as técnicas utilizadas no modelo de seleção por competências em duas empresas representativas no Estado brasileiro, além de verificar a opinião dos profissionais de recursos humanos acerca das dificuldades e dos benefícios no processo de seleção por competências. Trata-se de um estudo descritivo-exploratório, com abordagem qualitativa, realizado mediante pesquisa de campo. Utilizouse a entrevista estruturada junto a dez profissionais da área de recursos humanos das empresas, objeto de estudo. Com base nas informações coletadas, concluiu-se que as técnicas mais empregadas são as seguintes: aplicação de testes psicológicos e específicos; uso de jogos e dinâmicas; e realização de entrevista comportamental. Quanto às dificuldades, foi apontado o tempo disponibilizado para conciliar os procedimentos inerentes a este modelo, em face das vagas emergenciais, e a formulação das perguntas feitas aos candidatos, capazes de captar a total sinceridade do candidato e as expectativas dos requisitantes acerca das competências realmente desejadas. No que tange aos benefícios, estes se fundamentam na objetividade, tendo como foco a demanda específica da vaga e a redução de custos, uma vez que a análise precisa do perfil das competências diminui os erros e a aderência à vaga, o que possibilita esboçar, detalhadamente, o perfil apropriado dos candidatos para as respectivas oportunidades. Além disso, proporciona melhores resultados à organização, visto alinhar as competências individuais às organizacionais, tornando, assim, seus processos mais eficazes.

Palavras-chave: gestão de pessoas; candidato; seleção por competências. 


\section{ABSTRACT}

The present work has the objective to analyze the techniques used in the selection model of abilities in two representative companies in the Brazilian state as well as verifying the opinion of the professionals of human resources concerning the difficulties and the benefits in the process selection of abilities. It is a descriptiveexploratory study, with a qualitative approach, carried out through field research. We used structured interview with ten professionals in the field of human resources of the companies, the object of study. On the basis of the collected information it was concluded that the most used techniques are: the application of psychological and specific tests; the games and the dynamics and the behavioral interview. About the difficulties, it was pointed the available time to conciliate the procedures inherent to this model face to the emergency vacancies; the formulation of the questions done to the candidates so that they can catch the total sincerity of the candidate and the requesters' expectations concerning the abilities really desired. In what refers to the benefits, these are based on objectivity, having as focus the specific demand of the vancancy; reduction of costs, since the precise analysis of the profile of the abilities diminishes the mistakes and adherence to the vacancy, which allows at great length, to sketch the appropriate profile of the candidates for the respective opportunities. Moreover, it provides better results to the organization, since aligning individual abilities to the organizations, thus making their processes more effective.

Keywords: People Management; Candidate; Selection of abilities.

\section{INTRODUÇÃO}

O recrutamento e a seleção de pessoas, dentro de uma organização, representam elevada importância, pois são as pessoas que compõem o ativo principal, necessário para o bom funcionamento de uma empresa. Falhas nesse processo comprometem a produtividade do trabalho e o desempenho das equipes nas organizações. Selecionar a pessoa adequada, encaminhando-a, naturalmente, para o lugar apropriado, significa a decorrência de um processo de seleção eficaz, além de agregar valores para os objetivos da empresa e demonstrar compromisso com o desempenho que o profissional virá a ter no cargo.

Diante deste aspecto, o processo de recrutamento e seleção é uma atividade que procura atender às necessidades internas da empresa, mediante métodos e técnicas específicas, criadas para atrair e escolher os melhores candidatos. Segundo LimongiFrança \& Arellano (2002), pode-se utilizar grande quantidade de instrumentos que proporcionam melhor qualidade e precisão a esses processos.

Recentemente, desenvolveu-se um novo método de seleção no mercado de trabalho. Trata-se da seleção por competências, e sua caracterização é constituída em função de tornar o processo de seleção mais ágil e objetivo, por ser proativo, ter visão estra- tégica e por apresentar a perspectiva de resultados no cargo e na função como foco principal.

Assim, a noção de competências pode apresentarse como referência a práticas próprias da gestão de pessoas, tais como seleção, desenvolvimento, avaliação e remuneração por competências (DuTRA, 2001 apud RuAs, Fleury \& Dutra, 2008). A transição para o conceito de competências pode ser associada aos impactos das transformações recentes, no ambiente de negócios, e à necessidade da área de gestão de pessoas em se adaptar às alterações estruturais, na organização do trabalho, tais como flexibilidade, multifuncionalidade e mudanças na natureza do trabalho (RUAS, FLEURY \& Dutra, 2008).

Neste contexto, faz-se necessário que a área de gestão de pessoas das empresas encontre novas referências de tratamento e gestão do trabalho, que sejam compatíveis ao novo ambiente, pois, de acordo Dutra (2004: 35):

Os grandes avanços vieram quando começamos a utilizar, com maior ênfase, o conceito de competência como entrega e agregação de valor e a ele incorporamos conceitos complementares: o de complexidade e o de espaço ocupacional. A incorporação desses conceitos permitiu estender o uso da competência para 
trabalhar com questões ligadas à carreira e remuneração. Durante a segunda metade da década de 90 (sic), foi possível observar a rápida evolução do uso do conceito, no aprimoramento da gestão de pessoas. Hoje, a articulação entre os conceitos de competências, complexidade e espaço ocupacional permite maior envolvimento dos gestores, na administração de pessoas e melhor avaliação das repercussões de suas decisões.

O grande objetivo da seleção por competências é criar um perfil de competências para cada cargo dentro da empresa, isto é, elaborar um mapeamento de competências que façam parte das estratégias de competitividade e diferenciação no mercado de trabalho (RABAglio, 2004). Seu principal mérito é o de possibilitar a seleção de pessoas com fundamento na definição das competências e habilidades necessárias para cada função, no sentido de facilitar tanto a identificação e aplicação de talentos quanto a implantação de políticas de pessoal e de planos de carreira. Sem contar que, à medida que a empresa adota a seleção por competências, passa a dispor de um sistema que possibilita verificar se a própria organização disponibiliza de colaboradores com qualificação e desempenho adequados às suas funções, contribuindo, dessa forma, para a viabilização de auditorias e obtenção de certificações.

Segundo Fleury (2002), o conceito de competência pode ser definido como o conjunto de conhecimentos, habilidades e atitudes que justificam um alto desempenho, acreditando-se que os melhores desempenhos estão fundamentados na inteligência e na personalidade das pessoas. Na visão da autora citada, competência representa uma palavra de senso comum, utilizada para designar a qualificação de uma pessoa para realizar determinada atividade. A qualificação é, normalmente, definida pelos requisitos relacionados ao cargo ou pelos saberes da pessoa, os quais podem ser classificados e certificados pelo sistema acadêmico. Já o conceito de competência está além do conceito de qualificação, pois se refere à capacidade da pessoa em ultrapassar as atividades prescritivas, assumir iniciativas, compreender e dominar novas situações no trabalho e ser reconhecida por isso. A competência do indivíduo não é um estado, ou seja, não se reduz a um conhecimento específico; ao contrário, está relacionada a "um saber agir res- ponsável e reconhecido, que implica mobilizar, integrar, transferir conhecimento, recursos, habilidades, que agreguem valor econômico à organização e valor social ao indivíduo" (FleUry \& FleURY, 2001).

Segundo as noções de competência destacadas por Zarifian (2003: 63), no contexto francês, trata-se de um "espaço de indeterminação e de não prescrição", que a ação do indivíduo ou do grupo competente deve preencher, ou ainda, "a expressão de capacidades individuais, singulares, no seio de um conjunto coletivo".

Sendo assim, percebe-se que tais definições caminham no mesmo sentido do debate desenvolvido pelos autores brasileiros, especialistas em competências. Diante desse aspecto, Dutra (2002: 126) assim definiu competência:

Competências da organização podem ser definidas como características de seu patrimônio de conhecimento, que lhe conferem vantagens competitivas no contexto em que se insere e as competências do indivíduo envolvem a capacidade da pessoa de agregar valor ao patrimônio de conhecimentos da organização.

Para o autor mencionado, competência é, na verdade, pôr em prática o que se sabe, em determinado contexto, marcado, geralmente, pelas relações de trabalho, pela cultura da empresa, por imprevistos, limitações de tempo, recursos etc.

Ressaltou Dutra, ainda, que as pessoas atuam como agentes de transformação de conhecimentos, habilidades e atitudes, em competência disponibilizada para a organização. A competência entregue pode ser caracterizada como agregação de valor ao patrimônio de conhecimentos da empresa, cabendo destacar que agregação de valor refere-se a algo que a pessoa entrega para a organização, de forma efetiva, ou seja, algo que fica mesmo quando a pessoa sai da organização. Portanto, a agregação de valor não se restringe a atingir uma meta de faturamento ou de produção, mas se preocupa com a melhoria de um processo ou a introdução de uma nova tecnologia.

Em corroboração à visão do autor supracitado, Ruas (2008: 59) afirmou que:

A competência organizacional, uma vez explicada na entrega, traduz determinada certifi- 
cação. É alinhada ao conceito de complexidade que consegue explicar a trajetória de desenvolvimento da empresa e sua real contribuição ao negócio. As organizações competem no mercado por complexidade, ou seja, pelo nível de agregação de valor de suas competências organizacionais. Desta forma, entende-se que sua noção ajude a esclarecer, por exemplo, como empresas com a mesma competência apresentam diferentes níveis de desempenho e atuação frente ao (sic) mercado.

Neste contexto, entende-se que os resultados obtidos pelas organizações, no desenvolvimento dos seus negócios, estão ligados às competências detidas por seus profissionais, e que o diferencial competitivo está no capital humano, representado pelos profissionais que demonstram, em seus comportamentos, conhecimentos, habilidades e atitudes necessárias para a realização de um desempenho superior, que proporcione à organização melhor qualidade em seus serviços e maior competitividade no mercado de atuação.

Entretanto, vale ressaltar que a organização não está sendo regida por princípios que privilegiem o humano em detrimento de outros valores organizacionais. Na realidade, quanto mais os negócios se sofisticam, em qualquer de suas dimensões - tecnologia, mercado, expansão e abrangência etc. -, mais seu sucesso fica dependente de um padrão de comportamento adequado a esses negócios (FISCHER, 2002).

No processo de seleção de pessoas, encontrar um profissional com todas as qualidades exigidas e que se adapte à organização não constitui tarefa fácil. Ainda não existe um método de total sucesso, garantido. Todos os procedimentos têm suas vantagens, mas, também, apontam desvantagens. Nesse panorama, a seleção por competências apresenta maiores chances de se organizar enquanto um processo eficaz, devido ao fato de ser mais prática e de garantir a capacidade de medir cada habilidade que os candidatos possuem para um bom desempenho no cargo pretendido.

Há de se considerar que a utilização de procedimentos de seleção por competências ainda é incipiente. Requer-se, portanto, a realização de investigações empíricas, com vistas a verificar em que medida os procedimentos adotados se adaptam à realidade das empresas.
Desta forma, o presente trabalho tem como finalidade buscar respostas para o seguinte problema de pesquisa: quais os benefícios e dificuldades encontrados pelas empresas no processo de seleção por competências?

Assim sendo, este artigo tem como objetivo verificar as técnicas utilizadas no processo de seleção por competências, no âmbito de duas empresas brasileiras e, também, verificar a percepção dos profissionais da área de recursos humanos dessas empresas acerca das dificuldades e dos benefícios no processo de seleção por competências.

\section{O PAPEL DOS PROFISSIONAIS DE RECURSOS HUMANOS NAS ORGANIZAÇÕES}

O papel dos profissionais de recursos humanos tem estado em intensa observação e avaliação nas últimas décadas. Mudanças no cenário socioeconômico têm provocado alterações importantes nas relações de trabalho. Os avanços observados têm levado as organizações a buscarem novas formas de gestão, com o intuito de melhorar o desempenho e alcançar resultados mais expressivos diante do mercado competitivo.

Dessa forma, grande parte das organizações passa por mudanças e transformações em sua estrutura e em seus processos, devido à busca contínua de se manterem atualizadas e competitivas no mercado. As alterações sofridas por meio dessas mudanças provocam constantes impactos na sociedade e na vida das pessoas, acelerando, cada vez mais, as mudanças ambientais.

Existem diversas empresas em que a área de recursos humanos, mediante políticas e procedimentos, proporciona soluções para que as pessoas possam desempenhar seu trabalho com maior eficácia, atentas a todas as necessidades pessoais e do ambiente social dentro da organização.

A evolução, na área de recursos humanos, é percebida, até mesmo, nos conceitos, pois, segundo Gil (2001: 18):

A expressão Gestão de Pessoas visa substituir a Administração de Recursos Humanos, que é o termo mais comum utilizado para designar os modos de lidar com as pessoas, nas organi- 
zações. Os argumentos em prol dessa mudança de nomenclatura ressaltam que o termo Administração de Recursos Humanos é muito restritivo, pois implica a percepção das pessoas que trabalham numa organização, apenas como recursos, ao lado dos recursos materiais e financeiros. Por isso mesmo, alguns autores, adeptos da Gestão de Pessoas, procuram designar às pessoas que trabalham nas organizações, não mais como empregados ou funcionários, mas como cooperadores e parceiros.

Cabe salientar que o modelo de gestão de pessoas representa a maneira pela qual uma empresa se organiza para gerenciar e orientar o comportamento humano no trabalho. Para isso, a empresa se estrutura definindo princípios, estratégias, políticas e processos de gestão (FISCHER, 2002).

Com intensidade cada vez maior, as organizações passam a investir na gestão de pessoas, que vai além dos conhecidos e tradicionais processos burocráticos de recursos humanos. Mais do que selecionar, contratar, cuidar dos benefícios e da folha de pagamento, a nova administração de recursos humanos tem uma visão ampla do negócio, participa do planejamento estratégico e trabalha pelo crescimento, desenvolvimento e sustentabilidade da organização.

Nesta perspectiva, Gil (2001) afirmou que a gestão de pessoas assume um papel de liderança, no sentido de ajudar as empresas a alcançarem a excelência organizacional e a enfrentarem os desafios competitivos. É necessário, no entanto, que a gestão de pessoas esteja vinculada aos objetivos das organizações, tais como a produtividade, a lucratividade, a integração, a satisfação e a motivação dos trabalhadores. Requer-se desta área que haja o comprometimento com a melhoria das organizações por intermédio de agilidade, proatividade e competitividade, além de valorização do capital humano, com o objetivo de permitir que as pessoas possam criar, inovar e opinar, apoiando a empresa como um todo.

\subsection{Processo de recrutamento e seleção de pessoas nas organizações}

A concorrência que existe entre as organizações para superar as expectativas e exigências dos consu- midores e do mercado, na era da informação, conhecimento e globalização, aumenta a cada dia. Isso faz com que as organizações busquem, constantemente, inovação, qualidade, criatividade, excelência e agilidade dentre as alternativas que as ajudem a se manter competitivas no mundo dos negócios. Por força da influência dessas variáveis, é de extrema importância que as organizações invistam em seu capital intelectual, atraindo profissionais aptos a atender às exigências e transformações propostas pelo contexto contemporâneo.

Segundo Limongi-França \& Arellano (2002), seleção é a escolha do candidato mais adequado para a organização, dentre todos os recrutados, por meio de vários instrumentos de análise, avaliação e comparação de dados.

Neste ínterim, Bohlander, Snell \& Sherman (2003) definiram seleção de pessoas como o processo de escolha entre os indivíduos com qualificações que atendam aos requisitos do cargo e às necessidades da organização. A meta geral da seleção é maximizar os acertos e evitar os erros. O custo de um tipo de erro seria a despesa direta ou indireta de contratar um colaborador que fracassa. Outro tipo de falha envolve um custo de oportunidade - alguém que poderia obter êxito e não teve oportunidade. As pesOsoas devem, portanto, ser recrutadas e selecionadas com a maior competência possível, já que as falhas nesse processo podem comprometer outras ações de gestão a serem desenvolvidas posteriormente (Gı, 2001).

\subsection{Gestão por competências}

A noção de gestão de competências, segundo Fischer (2002), está relacionada à ênfase na competição, sendo constatada nas obras de autores como Porter, Hamel e Prahalad, e direciona, de forma decisiva, toda a teoria organizacional na criação das bases do surgimento de um modelo de gestão de pessoas, fundamentado em competências.

O método de gestão por competências pode ser definido como o conjunto de procedimentos que o gestor utiliza para identificar, em um candidato, um agrupamento de atitudes, conhecimentos e habilidades convertidas em resultados. Nesse sentido, Rabaglio (2004: 2) argumentou que: 
Ser competente está relacionado com um bom desempenho numa determinada tarefa, o que não garante que esse desempenho será bom sempre. Ter competência para a realização de uma tarefa significa ter conhecimentos, habilidades e atitudes compatíveis com o desempenho dela e ser capaz de colocar esse potencial em prática, sempre que for necessário. Então, podemos definir competência como um conjunto de conhecimentos, habilidades, atitudes e comportamentos que permitem ao indivíduo desempenhar com eficácia determinadas tarefas, em qualquer situação.

Assim sendo, competência pode ser definida como características de um profissional que possui a excelência em prestar serviços com qualidade, a fim de tornar a empresa que trabalha mais competitiva no mercado. Desta forma, para Eboli (2002), as competências humanas devem ser contraídas e desenvolvidas em cada indivíduo, possibilitando bons resultados nos alvos estratégicos da organização, tendo habilidades de mercado, administrativas, comportamentais e técnicas no exercício das tarefas críticas da empresa. É preciso pensar nos fundamentais pontos de análises desenvolvidas nas competências empresariais.

Nessa perspectiva, percebe-se que o diferencial competitivo está no capital humano, na capacidade que a empresa tem de possuir profissionais competentes. Com base nisso, as organizações buscam a valorização e o reconhecimento desse capital, e os gestores têm um papel prioritário como agentes de mudanças desse processo.

É importante que as empresas detectem as capacidades individuais das pessoas, já que estas precisam estar atreladas às competências organizacionais. Tais capacidades são definidas pelo que a empresa é capaz de fazer de modo superior ao da sua concorrência. A identificação das competências organizacionais é necessária para orientar nas decisões quanto às atividades que são cruciais para o sucesso da organização. Ainda segundo Eboli (2002), as competências empresariais diferenciam a empresa estrategicamente, e, por possuí-las, a organização aumenta sua capacidade de competir no setor atuante.

Nesse contexto, a gestão por competências considera o fator humano como um elemento que interfere em todas as atividades organizacionais, alinhan- do seus conhecimentos, habilidades e atitudes aos requisitos de suas funções. Para se captar um profissional que possua esses atributos, se faz necessária a utilização de uma técnica minuciosa de seleção, sendo que, por meio de etapas de avaliação, será possível alcançar um perfil considerado ideal.

\subsection{Seleção por competências}

Na competitividade do mundo capitalista, o que conta são as competências das organizações, pois quem não tem competência para competir não tem capacidade para se manter num mercado em que as tendências de inovações e a qualidade de serviços entre concorrentes têm crescido de forma acelerada. É necessário à empresa se equipar de profissionais altamente capazes e talentosos, que satisfaçam os requisitos atuais, treinando os que já estão atuando nela e selecionando, criteriosamente, aqueles que adentrarão e desempenharão tarefas na companhia (Almeida, 2004).

Segundo Rabaglio (2008), o crescente avanço da concorrência dos negócios força as companhias a adquirirem as competências que elas trataram com negligência em ocasiões anteriores, de modo a diminuir a concorrência e aumentar facilidades para obter lucros e crescer. Todo esse processo trouxe à tona a seleção por competências, sendo a forma mais ajustada e objetiva de realizar a seleção de pessoas, atrelada às táticas da empresa por meio de algumas técnicas.

A seleção por competências tem por finalidade trazer para a organização um profissional que possa desenvolver seu potencial de forma contínua, realizando funções pertinentes ao cargo com eficiência, eficácia e responsabilidade. Para Rabaglio (2004), o objetivo deste método é trabalhar com o foco bem definido. Selecionadores e requisitantes necessitam se comunicar de forma clara num mesmo universo discursivo. Uma das características fundamentais da seleção por competências é o fato de a mesma não se fundamentar na intuição, no processo de escolha de um candidato, e sim em fatos reais e dimensíveis, como a conduta. Com isso, agrega-se maior segurança na assertividade de contratação.

Assim sendo, para Limongi-França \& Arellano (2002), a seleção de pessoal não pode ser feita apenas pela avaliação de experiência e do conhecimento 
do trabalho a ser realizado, pois, de acordo com Rabaglio (2004), a diferença entre a seleção tradicional e a seleção por competências organiza-se da seguinte maneira: a primeira possui pouca consistência e a análise de comportamento é uma questão particular. Entretanto, a seleção por competências privilegia a observação da conduta e das características das pessoas, sendo realizada mediante técnicas específicas. Tal procedimento evidencia foco e objetividade na identificação do candidato possuidor de competências compatíveis com as competências organizacionais. Todo este processo tem como consequência um resultado mais eficaz no processo de atração de talentos.

Nesse sentido, Rabaglio (2004) argumentou que competência é composta pelo CHA (conhecimento, habilidade e atitude), ao qual devem estar agregadas as competências técnicas e comportamentais de cada indivíduo, sendo a primeira referente a conhecimento e desenvoltura em técnicas ou desempenhos específicos e a segunda, em maneiras e condutas compatíveis com as atribuições das tarefas a serem executadas.

Dentre as principais competências observadas nos indivíduos, estão as enumeradas na sequência: adaptabilidade com as mudanças e situações duvidosas; capacidade de pensar taticamente; habilidade de tomar decisões ajustadas diante de pressão e de tomar decisões com exatidão; disposição para trabalhar aprendendo com colegas de trabalho; aptidão para trabalhar em equipe; sabedoria para negociar quando houver problema; proficiência para se sobressair de situações difíceis; diferenciar trabalho da vida pessoal; manutenção de bom humor; e faculdade de ser flexível.

Muitas empresas, no mundo atual, precisam se abastecer de competências e talentos para estar aptas e acompanhar a evolução do mercado e, assim, sobreviver. A dominação de algumas competências faz diferença no contexto profissional. Organizações que se comportavam como se tivessem talentos de sobra veem-se diante de um cenário novo: mostram dificuldades para identificar, em seus próprios quadros, profissionais que atendam à demanda de competências exigida pelo mundo globalizado (GramignA, 2004: 11).

Rabaglio (2004) afirmou que a seleção baseada em competências apresenta diversas vantagens para as organizações, podendo ser destacadas as seguintes: proporcionar boa adequação do profissional à empresa e à atividade a ser desempenhada, possuir um processo sistemático com mais foco e objetividade, ser mais consistente na identificação de comportamentos relevantes para a vaga, ter maior facilidade na avaliação do desempenho futuro, conferir maior garantia de contratação de sucesso, evitar prejuízos com reabertura de processos seletivos e com funcionários ineficientes, garantir turnover mais baixo e, consequentemente, aumentar a produtividade. Por outro lado, Gramigna (2004) relatou que a seleção por competência é um método bastante eficaz, porém, quando aplicado de forma incorreta, pode gerar algumas dificuldades para os profissionais de recursos humanos.

Nesse contexto, Rabaglio (2008) advertiu acerca da importância da percepção do avaliador em descrever com exatidão a realidade objetiva do candidato para que não haja falhas no processo, tendo que tratar, de modo criterioso, sua análise sem perder a origem ética. A referida autora afirmou, também, que seria útil comover, conscientizar, direcionar especificamente e habilitar o gestor, tornando-o seguro na avaliação, de modo a aproximar-se da finalidade que se recomenda.

\section{MÉTODO}

A presente pesquisa tem um caráter exploratóriodescritivo, com abordagem qualitativa, já que apresenta como objetivo verificar os benefícios e dificuldades encontrados no processo de seleção por competências, sob a ótica de profissionais de gestão de pessoas de duas empresas brasileiras. Seu caráter exploratório se deve ao fato de ter como objetivo primordial ampliar a compreensão das pesquisadoras, em relação ao fenômeno investigado (SELltiz et al., 1974). Seu caráter descritivo, por sua vez, decorre do fato de permitir a descrição das unidades de estudo, constituídas por duas empresas, cujo âmbito foi estudado o fenômeno (Gı, 2007).

Foi realizada, também, a pesquisa de campo que, segundo Marconi \& Lakatos (2005), consiste na procura de resposta para uma hipótese que se queira comprovar, ou a descoberta de novos fenômenos, objetivando conseguir informações e/ou conhecimentos acerca de um problema. Para tanto, foram feitas 
entrevistas orientadas, representadas por um roteiro com questões estruturadas, tendo como objetivo uma melhor comparação nos resultados finais junto aos colaboradores da área de recursos humanos de duas empresas: a DHL (Dalsey, Hillblom e Lynn), que atua no setor de transporte aéreo, expresso internacional e de logística, e a ADP (Automatic Data Processing), que atua com sistema e serviços de folha de pagamento e recursos humanos.

As entrevistas foram realizadas com dez profissionais da área de recursos humanos das organizações mencionadas, tendo como objetivo analisar as dificuldades e os benefícios por eles encontrados no processo de seleção por competências, além de verificar os procedimentos utilizados por essas empresas nesse método de seleção. A entrevista estruturada permite uma melhor comparação entre as respostas dos entrevistados, pois existe um padrão de perguntas. Reflete, também, as diferenças somente entre os respondentes, e não nas questões (Marconi \& LaKatos, 2005).

\section{ANÁLISE DOS RESULTADOS}

Como mencionado na seção anterior, os participantes da pesquisa são profissionais da área de recursos uumanos das empresas ADP e DHL, que atuam ou já atuaram na área de recrutamento e seleção, e utilizam ou já utilizaram o método de seleção com foco em competências.

Os dados foram analisados mediante a comparação de sete itens definidos pelas autoras, como conceitos analisados no processo de seleção por competências e a opinião de dez profissionais da área de recursos humanos, sendo cinco profissionais da empresa ADP e cinco profissionais da empresa DHL. Desta forma, a análise de dados foi realizada a partir do conteúdo obtido com as respostas fornecidas pelos participantes. As informações foram transcritas e interpretadas com a reunião das opiniões dos pesquisados.

Diante disso, tendo como base a fundamentação teórica, foram analisadas as diferentes definições de cada participante da pesquisa a respeito dos métodos e conceitos sobre o tema proposto, de forma qualitativa, que foi definida por Gil (2007) como uma sequência de atividades que envolve a redução dos dados, a categorização desses dados, sua interpretação e a redação do relatório.

\subsection{Perfil das organizações, objeto de estudo}

\subsubsection{Empresa Automatic Data Processing - ADP}

A ADP (Automatic Data Processing) foi fundada em 1949, em Nova Jersey (EUA), e está presente em 26 países. Atua no ramo de serviços de organização, automação de processos, processamento de informações em sistemas e serviços de folha de pagamento e recursos humanos. Conta com um quadro de pessoal composto por 37 mil colaboradores em todo o mundo. No Brasil, iniciou suas atividades em 1966 e possui 750 colaboradores.

\subsubsection{Empresa DHL (Dalsey, Hillblom e Lynn)}

A DHL (Dalsey, Hillblom e Lynn) foi fundada em 1969, na cidade de São Francisco, nos Estados Unidos, e está presente em mais de 220 países. Atua no segmento de transporte aéreo, expresso internacional e de logística. Possui cerca de 300 mil colaboradores em todo o mundo. No Brasil, seu quadro de pessoal é composto por seis mil colaboradores.

\subsection{Profissionais da área de Recursos Humanos das empresas ADP e DHL}

Por meio das informações obtidas na coleta de dados, foram realizadas as análises dos resultados e expostas por meio de conceitos baseados nas questões elaboradas aos participantes da pesquisa. Nas tabelas a seguir, será ilustrado o perfil dos participantes pesquisados, ressaltando que todos foram nomeados como sujeitos para a preservação de suas identidades.

Tabela 1: Pesquisados da Empresa ADP

\begin{tabular}{llcc}
\hline \multicolumn{4}{c}{ Pesquisados da Empresa ADP } \\
\hline Sujeitos & \multicolumn{2}{c}{ Cargo ocupado Tempo de atuação } & Sexo \\
\hline Sujeito A & Assistente de RH & 1 ano & Feminino \\
\hline Sujeito B & Analista de RH Jr. & 1 ano & Feminino \\
\hline Sujeito C & Analista de RH Jr. & 2 anos & Feminino \\
\hline Sujeito D & Analista de RH Sr. & 3 anos & Feminino \\
\hline Sujeito E & Consultora de RH & 11 meses & Feminino \\
\hline
\end{tabular}

Fonte: dados da pesquisa (2009). 
Tabela 2: Pesquisados da Empresa DHL

\begin{tabular}{lccc}
\hline \multicolumn{4}{c}{ Pesquisados da Empresa DHL } \\
\hline Sujeitos & Cargo ocupado & Tempo de atuação & Sexo \\
\hline Sujeito F & Analista de RH & 5 anos & Feminino \\
\hline Sujeito G & Analista de RH & 4 anos & Feminino \\
\hline Sujeito H & Analista de RH & 6 anos & Feminino \\
\hline Sujeito I & Analista de RH & 1 ano & Feminino \\
\hline Sujeito J & Supervisora de RH & 16 anos & Feminino \\
\hline
\end{tabular}

Fonte: dados da pesquisa (2009)

As mulheres possuem características que facilitam a gestão de pessoas, e uma delas é a habilidade de lidar com os indivíduos em geral, articular e integrar. Hoje, esta é uma necessidade crucial de toda organização. Desta forma, a área de recrutamento e seleção das empresas é constituída, principalmente, por profissionais da área de psicologia, em que as muIheres constituem a maioria.

A seguir, os conceitos analisados a partir do roteiro de entrevista respondido pelos participantes.

\subsection{Conceitos analisados no processo de seleção por competências sob a ótica dos profissionais da área de Recursos Humanos das empresas ADP e DHL}

Quadro 2: Conceitos analisados no processo de seleção por competências

\begin{tabular}{|l|}
\hline \multicolumn{1}{|c|}{ Conceitos analisados } \\
\hline 1. Significado de competência \\
\hline 2. Significado de seleção por competência \\
\hline 3. Técnicas utilizadas nesse método de seleção \\
\hline 4. Construção e escolha das técnicas \\
\hline $\begin{array}{l}\text { 5. Dificuldades encontradas no processo de seleção por } \\
\text { competência }\end{array}$ \\
\hline $\begin{array}{l}\text { 6. Benefícios encontrados no processo de seleção por } \\
\text { competência }\end{array}$ \\
\hline 7. Critérios utilizados para avaliação final \\
\hline
\end{tabular}

Fonte: dados da pesquisa (2009).

\subsubsection{Significado de competência}

As respostas fornecidas pelos participantes da pesquisa em relação ao item número um dos conceitos analisados (significado de competência) apontam para duas categorias conceituais em relação a este item. Os entrevistados definiram competência como habilidade do indivíduo que atende às exigências do cargo. Dentre estas respostas, vale destacar uma definição proposta:

Competência está envolvida na capacidade e habilidade que determinado profissional deve ter ao desenvolver determinadas funções [...] (Sujeito G).

Assim, é notável a existência de participantes que a conceituam como um conjunto de conhecimentos, habilidades e atitudes. A conceituação da competência como habilidade do indivíduo que atenda às exigências do cargo é explicada pelo fato de o profissional possuir capacidade para desenvolver as atividades de determinada função com eficácia. Enquanto a conceituação for tratada dessa forma, é possível justificar que características essenciais num profissional potencial devem ser agregadas às expectativas da empresa. As respostas apresentadas corroboram os pressupostos teóricos de Rabaglio (2004), segundo os quais competência é um conjunto de conhecimentos, habilidades, atitudes e comportamentos que permitem ao indivíduo desempenhar com eficácia determinadas tarefas em qualquer situação.

Essas respostas assemelham-se à definição proposta por Fleury (2002), ao afirmar que competência é o conjunto de conhecimentos, habilidades e atitudes que justificam um alto desempenho, fundamentados na inteligência e na personalidade das pessoas. Tal conceituação foi ressaltada, também, por Dutra (2002), que disse: "as pessoas atuam como agentes de transformação de conhecimentos, habilidades e atitudes em competência entregue para a organização".

Observa-se que os entrevistados possuem uma conceituação adequada do tema, o que se torna relevante e necessário para que possam conduzir um processo de seleção por competências, como se verá no próximo item.

\subsubsection{Significado de seleção por competências}

A questão "significado de seleção por competências", que é o segundo item dos conceitos analisados, tem o propósito de verificar a opinião dos entrevistados acerca do significado de seleção por competências. Na visão dos entrevistados, este tipo de seleção é sinônimo da identificação do candidato mais 
apto a desenvolver as atividades da vaga oferecida. Dentre as respostas fornecidas, uma delas destacouse por conceituar o seguinte:

Seleção por competências envolve a contratação de colaboradores que se encaixam e/ou se aproximam ao máximo possível do perfil da função / atividade a ser desempenhada [...] (Sujeito J).

Alguns profissionais entrevistados atribuem o conceito central deste item como identificação de adequação com a vaga por intermédio de comportamento, habilidades e experiências anteriores. Um deles declarou que seleção por competências baseiase no comportamento do candidato e mede suas habilidades a partir do seu discurso:

Com este modelo, conseguimos pedir que relate experiências anteriores ou sugerir estudos de caso para avaliar a reação do candidato em questão [...] (Sujeito F).

As respostas apresentadas por todos os participantes encontram respaldo na fundamentação teórica defendida por Rabaglio (2004), que, em seus pressupostos, argumentou ser a seleção por competências a possibilidade do uso de técnicas específicas. Neste caso, segundo os entrevistados, a aplicação de testes, inclusive os psicológicos, revela que são técnicas eficazes que apontam o candidato mais adequado às exigências do cargo. A relevância das técnicas utilizadas também foi ressaltada por Gramigna (2004), ao demonstrar que, para a organização avaliar o potencial e a formação de talentos, é necessária a assimilação de habilidade por meio da técnica análise de grupo de estudos, para que possa identificar a capacidade do indivíduo em exercer determinadas atividades. Esta assimilação de habilidades poderá ser mensurada pelo uso de técnicas específicas neste método específico de seleção por competências, conforme descrito a seguir.

\subsubsection{Técnicas utilizadas na seleção por competências}

Em relação às técnicas utilizadas na seleção por competências, as entrevistas baseadas em perguntas técnicas e comportamentais foram as que mais se destacaram. Um dos participantes exemplificou como:

Perguntas técnicas que focam conhecimentos e comportamentos que são fundamentados em análises situacionais [...] (Sujeito D).
Para este grupo, as entrevistas baseadas em perguntas técnicas têm como finalidade constatar o conhecimento e práticas ligadas à função a ser exercida, sendo examinadas em avaliações que se baseiam, especificamente, no conhecimento do candidato. As entrevistas comportamentais consistem em indagações voltadas ao passado, comparadas às condutas ou situações adversas. Também atribuem como técnicas utilizadas na seleção por competências as ferramentas que possibilitam identificação de um perfil consistente, detalhando com perguntas direcionadas e abertas, sendo estas vinculadas à experiência profissional do candidato. Portanto, para este grupo de profissionais, as técnicas utilizadas na seleção por competências compreendem um conjunto de ações. Um dos respondentes sintetizou e exemplificou esta classificação de técnica quando declarou que:

[...] As técnicas são usadas mediante elaboração do perfil da vaga com o requisitante, triagem de currículo X perfil do cargo, aplicação de teste e dinâmica, finalizando com a entrevista feita com o requisitante [...] (Sujeito J).

Com isso, pode-se perceber que as técnicas utilizadas nos processos seletivos, com base no modelo de seleção por competências, são direcionadas para avaliar os aspectos técnicos e comportamentais. A identificação desta performance comportamental é avaliada no processo de aplicação das dinâmicas de grupo e perguntas específicas realizadas durante a entrevista, denominada no modelo de seleção por competências como entrevista comportamental com foco em competências. Segundo Rabaglio (2001), trata-se de um modelo de entrevista utilizado na investigação dos comportamentos anteriores dos candidatos. Dentre seus diferenciais, destaca-se o fato de ser uma entrevista estruturada e planejada, com base no perfil das competências. Por isso, é uma entrevista personalizada a cada perfil de competência e a cada processo seletivo. As perguntas são abertas e específicas, com verbos de ação no passado. Sendo assim, o processo de construção e escolha destas técnicas merece uma atenção especial.

\subsubsection{Construção e escolha das técnicas}

Nesta seção, serão demonstradas as análises do processo de escolha, das técnicas utilizadas pelos 
entrevistados no processo de seleção por competências. Segundo os entrevistados, este processo tem início no contato com o requisitante da vaga, quando, então, é traçado o perfil de competência exigido pela vaga. Um deles apontou:

Primeiro é elaborado, junto ao requisitante, o perfil de competências exigido pelo cargo onde será possível elaborar a entrevista, jogos e testes baseados nessas competências [...] (Sujeito E).

Os participantes afirmaram, também, que a formulação das técnicas é feita com base na complexidade do cargo. Um dos entrevistados exemplificou como isto é feito:

Através da complexidade do cargo, são definidas junto ao requisitante as técnicas que melhor avaliarão o conhecimento, capacidade e experiência dos candidatos (Sujeito G).

Com base nas respostas obtidas, pode-se verificar que, a partir do contato com o requisitante da vaga e do mapeamento de competências exigidas pelo cargo, são construídas e escolhidas as técnicas que melhor identificarão os conhecimentos, a capacidade e a experiência dos candidatos, resultando numa escolha eficaz. Segundo Rabaglio (2004), o processo de construção e escolha de técnicas é de extrema importância para que as competências de cada processo seletivo sejam bem definidas e condensadas.

\subsubsection{Dificuldades encontradas no processo de seleção por competências}

Para analisar as respostas dos entrevistados referentes a esta questão, adotou-se, também, o processo de categorização em relação aos dados apurados. Diferentemente das análises anteriores, neste item, foram organizadas quatro categorias. A primeira - "não percebe dificuldades" - foi apontada por apenas um dos sujeitos pesquisados, o qual justificou a não existência de dificuldades pelo fato de o processo oferecer recursos para uma seleção bem elaborada, resultando em contratações assertivas. A segunda categoria foi constituída por duas das entrevistadas, as quais atribuíram o fator "tempo" como o dificultador do processo de seleção por competências. A referência, no caso, é feita a duas pessoas das quais, sendo que uma delas exemplifica esta dificuldade relacionada ao quesito "tempo":
O fator tempo, porque muitas vezes são vagas emergenciais [...] (Sujeito F).

Observa-se, assim, que a dificuldade encontrada pelo fator "tempo" foi mencionada pelo fato de o processo de seleção por competências ser minucioso e exigir atenção a cada detalhe, o que dificulta a sua utilização para vagas emergenciais. A terceira categoria corresponde às dificuldades encontradas no processo de seleção por competências em função da "formulação de perguntas". Para cinco pessoas, a dificuldade de formular perguntas é encontrada por conta da percepção da sinceridade dos candidatos.

Na quarta e última categoria das dificuldades encontradas, duas das entrevistadas a justificaram em função da dificuldade de traduzir as expectativas dos requisitantes acerca do comportamento e das habilidades exigidas para o desempenho da função. Correlacionando as categorias aos pressupostos teóricos, observou-se que para a segunda categoria, o fator "tempo", apontado pelos participantes, está amparado pela percepção de Gramigna (2004), ao relatar que as organizações pecam ao não disponibilizar tempo para debater fatores importantes, relacionados ao plano de avaliação de potencial de talentos.

Para a terceira categoria das dificuldades encontradas no processo de seleção por competências, ou seja, a "formulação de perguntas", o respaldo teórico encontra eco na teoria de Leme (2008), quando este afirmou que a resistência das empresas ao método de seleção por competências acontece em razão de experiências sem sucesso, associado ao uso incorreto do processo em questão, por parte dos selecionadores. Entretanto, quando as empresas conseguem ter uma melhor visão desse processo, essa resistência se transforma em aceitação. Essa dificuldade foi também apontada pelos pressupostos de Gramigna (2004), quando esta alegou que o selecionador, por falta de adaptação ao método de competências, aplica de forma errada os instrumentos de análise de competências.

A dificuldade apontada na quarta categoria, ou seja, "comportamento das competências requeridas", é corroborada pela visão de Rabaglio (2004), quando a referida autora afirmou que a seleção se torna um momento crítico quando o selecionador se depara com dificuldades para encontrar um candidato que se encaixe perfeitamente no perfil almejado pela empresa, por não utilizar técnicas que meçam as 
competências dos candidatos de forma eficaz. Neste contexto, Almeida (2004) relatou que, às vezes, o requisitante não tem, nitidamente, definidas quais competências são eficazes para uma atividade, tornando mais trabalhosa a preparação de um perfil ideal para a vaga em questão.

\subsubsection{Benefícios encontrados no processo de seleção por competências}

Quatro categorias foram delineadas para analisar as respostas dos profissionais de recursos humanos em relação a esta variável do estudo. A primeira delas reuniu os benefícios nos itens: "objetividade, ou seja, maior facilidade para prever o desempenho futuro". Esta categoria é explicada pela conciliação do perfil com as práticas da tarefa, visto que o método amplia os resultados das equipes, em geral proporcionando segurança para a concretização dos processos seletivos, o que diminui as probabilidades de fingir ou mentir. Afinal, sendo a mesma objetiva, analisam-se precisamente as atribuições da vaga requisitada, pelo fato de existir uma pré-conferência do perfil atrelado à tarefa.

A segunda categoria está relacionada à "redução de custos" e é explorada por meio das ferramentas que os selecionadores utilizam para analisar se conhecimentos, habilidades e atitudes ofertados pelos candidatos realmente vão ao encontro do perfil almejado. Tal procedimento possibilita a assertividade na escolha e menor possibilidade de erro, evitando custos com o retrabalho de novas contratações feitas pela área de recursos humanos.

A terceira categoria se refere à "identificação de outras habilidades, além das esperadas", que poderão ser agregadas aos cargos existentes na empresa, sendo vista pelos participantes como um benefício, pois, com isso, a empresa evita custos maiores. A partir da implantação do modelo de seleção por competências, os selecionadores passam a efetivar suas habilidades para avaliar as competências existentes no candidato, que são correlatas às competências organizacionais.

A quarta e última categoria deste item atribui como benefício do modelo de seleção por competências a "aderência à vaga". Esta análise é fundamentada no fato de que o modelo de seleção por competências possibilita esboçar, detalhadamente, o perfil apropriado dos candidatos para as respectivas vagas. Além disso, graças ao uso da técnica de entrevista comportamental com foco em competências, já apresentado anteriormente, é possível projetar o comportamento futuro do candidato, com base em suas ações no passado, e examinar, portanto, como o postulante à vaga possivelmente se comportará no dia a dia profissional, seja em situações de pressão, seja nos relacionamentos interpessoais ou em situações que demandem a tomada de decisões.

O panorama das quatro categorias analisadas encontra respaldo na teoria de Rabaglio (2004). Esta autora afirmou que a seleção com foco em competências proporciona às organizações diversas vantagens, destacando a boa adequação do profissional à empresa e à atividade a ser desempenhada, no sentido de possuir um processo sistemático, com mais foco e objetividade; ser mais consistente na identificação de comportamentos relevantes para a vaga; apresentar maior facilidade na avaliação do desempenho futuro e maior garantia de contratação de sucesso, com vistas a evitar prejuízos com a reabertura de processos seletivos e com colaboradores ineficientes.

\subsubsection{Critérios utilizados para avaliação final do candidato}

Questionadas acerca dos critérios utilizados e analisados para a avaliação final dos candidatos, as profissionais entrevistadas apresentaram respostas que se enquadram em duas categorias. A primeira delas compreende o "confronto de dados", sendo sinalizado por cinco das entrevistadas. Esta variável é, assim, conceituada em função da avaliação quanto à veracidade das respostas apresentadas pelos candidatos durante a entrevista. Isto é feito mediante a aplicação dos testes. Tal procedimento permite e confirma o diagnóstico daqueles que estão de acordo com o perfil preestabelecido, ou seja, aqueles candidatos que demonstram possuir competências e traços dentro do perfil delineado pela organização e que possam desenvolver-se em sintonia com as exigências do cargo proposto.

A segunda e última categoria analisada neste item refere-se ao indicador viabilizado por meio da entrevista com o gestor da área. Tal conduta é realizada após a elaboração do parecer da entrevista, feita pelas profissionais da área de recursos humanos, somadas aos resultados dos testes e dinâmicas de 
grupo realizadas. As informações contidas neste material possibilitam a redução de falhas na escolha do candidato. Vale ressaltar que a avaliação e a escolha final do candidato são feitas e ficam sob a responsabilidade do gestor da área.

\section{CONSIDERAÇÕES FINAIS}

Ao término deste artigo, são tecidas algumas considerações relacionadas ao modelo de seleção por competências, em função de o mesmo envolver a verificação de aspectos ligados às competências organizacionais e individuais. Diante disso, verificouse que o processo de seleção, realizado a partir deste modelo, conduz à realização de mudanças, integração, mobilização e desenvolvimento da atuação e do desempenho da área de recursos humanos, modernamente denominada gestão de pessoas. Estas transformações ampliam os benefícios organizacionais, pois a utilização de tal critério para a inclusão de colaboradores em seu quadro pode ser considerada um investimento assertivo, em função de adequar as competências profissionais do colaborador às necessidades organizacionais da empresa, podendo gerar lucratividade.

Neste contexto, a pesquisa realizada teve como propósito analisar as técnicas adotadas no processo de seleção por competências e, principalmente, verificar as dificuldades e os benefícios encontrados pelos profissionais de gestão de pessoas, na aplicação desse modelo de seleção.

Constatou-se que as duas empresas pesquisadas utilizam-se do modelo de seleção por competências, pois, a partir dos resultados obtidos pelas entrevistas junto aos profissionais que estão envolvidos neste processo, foi verificado que o modelo em questão envolve a identificação e a contratação do candidato mais apto à vaga oferecida, tendo em vista as competências organizacionais delineadas pela empresa. Segundo eles, para garantir a eficácia deste modelo em todo o processo, é preciso acompanhar, controlar e mensurar os indicadores que revelam o desempenho do próprio processo e que garantem os resultados.

Quanto às técnicas utilizadas no processo de seleção por competências nas empresas pesquisadas, observouse que as mais empregadas são as seguintes: aplicação dos testes psicológicos e específicos; uso de jogos e dinâmicas; e realização da entrevista comportamental, com foco em competências. Toda esta estrutura é delineada a partir do mapeamento do perfil de competências anteriormente validado junto ao requisitante da vaga. No entanto, este modelo reserva benefícios e dificuldades como todo e qualquer processo.

Assim, de acordo com as respostas obtidas pelos participantes, foi possível verificar que os benefícios da seleção por competências se fundamentam na objetividade, tendo como foco a demanda específica da vaga na promoção da redução de custos, uma vez que uma análise precisa do perfil das competências diminui os erros e cessam os custos gerados pelo retrabalho de contratação. Outro benefício apontado pelos entrevistados refere-se à aderência à vaga, promovida por meio de análises meticulosas das competências técnicas e comportamentais que apontam o perfil mais ajustado ao cargo. Todo este processo é desencadeado pelo mapeamento do perfil adequado e conciliado às competências organizacionais.

Diante deste aspecto, as dificuldades elencadas pelos entrevistados em relação ao modelo de seleção por competências passam por três pontos fundamentais: o tempo disponibilizado para conciliar os procedimentos inerentes a este modelo, em face das vagas emergenciais; a formulação das perguntas feitas aos candidatos, para minimizar a emissão de respostas daqueles que não correspondam totalmente à realidade dos fatos; e a interpretação das expectativas dos requisitantes acerca do comportamento e das habilidades realmente desejadas para compor o mapeamento e o perfil das competências necessárias à vaga.

Mediante as dificuldades apresentadas, é possível delinear ações futuras que se fazem necessárias ao desenvolvimento e ao desempenho dos especialistas em recursos humanos, em sua atuação profissional nos pontos que cabem um gerenciamento, ou seja, a formulação e a elaboração de perguntas que possam trazer à tona as reais competências individuais existentes nos candidatos, e que se revelem compatíveis com as competências organizacionais. Este é um tema que se anuncia para estudos posteriores. Quanto às demais questões envolvidas - o tempo para condução do processo e a interpretação das demandas apresentadas pelos requisitantes -, tratase de aspectos que dizem respeito ao alinhamento das estratégias e das políticas organizacionais, também assuntos para próximos estudos. 
Até aqui, observou-se que os profissionais entrevistados possuem domínio em relação ao modelo pesquisado, conhecem o significado da palavra central competência -, bem como o processo de seleção por competências. Por outro lado, possuem domínio das técnicas utilizadas para este método e, em consequên- cia disso, conduzem com tranquilidade a construção e a escolha destas técnicas. Por isso, a análise dos benefícios e das dificuldades para a condução deste processo, foco da presente pesquisa, possibilita-lhes o domínio para discernir os eventos existentes e apontar os possíveis caminhos para a melhoria contínua.

\section{REFERÊNCIAS}

Almeida, Walnice. Captação e seleção de talentos repensando a teoria e a prática. São Paulo: Atlas, 2004.

Bohlander, George; Snell, Scott \& Sherman, Arthur. Administração de Recursos Humanos. São Paulo: Pioneira, 2003.

Recursos Humanos: o capital humano das organizações. 8. ed. São Paulo: Atlas, 2004.

DHL - Dalsey, Hillblom e Lynn. Site institucional. Disponível em: <www.dhl.com.br>. Acesso em: 21 de marco de 2009.

Dutra, Joel Souza. Gestão de pessoas: modelos, processos, tendências e perspectiva. São Paulo: Atlas, 2002.

Ebou, Marisa. O desenvolvimento das pessoas e a educação corporativa. In: Fleury, Maria Tereza Leme (org.). As pessoas na organização. São Paulo: Gente, 2002.

Faria, Ana Cristina de; Cunha, Ivan da \& Felipe, Yone Xavier. Manual prático para elaboração de monografias: trabalhos de conclusão de curso, dissertações e tese. São Paulo: Universidade São Judas Tadeu, 2007.

FISCHER, André Luiz. Um resgate conceitual e histórico dos modelos de gestão de pessoas. In: Fleury, Maria Tereza Leme (org.). As pessoas na organização. São Paulo: Gente, 2002.

Fleury, Afonso \& Fleury, Maria Tereza Leme. Estratégias empresariais e formação de competências: um quebra cabeças caleidoscópico da indústria brasileira. São Paulo: Atlas, 2001.

Fleury, Maria Tereza Leme. A gestão de competência e a estratégia organizacional. In: FleURY, Maria Tereza Leme (org.). As pessoas na organização. São Paulo: Gente, 2002.
GIL, Antonio Carlos. Como elaborar projetos de pesquisa. 4. ed. São Paulo: Atlas, 2007.

Gestão de pessoas: enfoque nos papéis profissionais. São Paulo: Atlas, 2001.

Gramigna, Maria Rita. Modelos de competências e gestão de talentos. São Paulo: Pearson/Makron Books, 2004.

Leme, Rogério O valor das competências na gestão de pessoas (on-line). RH.com,br, 2008. Disponível em: <http://www.rh.com.br/Portal/Desempenho/ Entrevista/4972/>. Acesso em: 17 de maio de 2009.

Limongl-França, Ana Cristina \& Arellano, Eliete Bernal. Os Processos de Recrutamento e Seleção. In: Fleury, Maria Tereza Leme (org.). As pessoas na organização. São Paulo: Gente, 2002.

Marconi, Marina de Andrade \& Lakatos, Eva Maria. Fundamentos da metodologia científica. 6. ed. São Paulo: Atlas, 2005.

Rabaglıo, Maria Odete. Ferramentas de avaliação de performance com foco em competência. Rio de Janeiro: Qualit Mark, 2008.

Seleção por competências. 4. ed. São Paulo: Educator, 2004.

Seleção por competências. São Paulo: Educator, 2001.

Ruas, Roberto; Fleury, Maria Tereza Leme \& Dutra, Joel Souza (orgs.). Competência: conceitos, métodos e experiências. São Paulo: Atlas, 2008.

Seltiz, Claire; Jahoda, Marie; Deutsch, Morton \& Cook, Stuart. Métodos de pesquisa nas relações sociais. São Paulo: EPU, 1974.

Zarifian, Philippe. O modelo da competência. Trajetória histórica, desafios atuais e propostas. 2. ed. São Paulo: Senac, 2003. 